\title{
Application of Artificial Neural Networks for Predicting Generated Wind Power
}

\author{
Vijendra Singh \\ Department of Computer Science and Engineering \\ The Northcap University \\ Gurgaon, India
}

\begin{abstract}
This paper addresses design and development of an artificial neural network based system for prediction of wind energy produced by wind turbines. Now in the last decade, renewable energy emerged as an additional alternative source for electrical power generation. We need to assess wind power generation capacity by wind turbines because of its nonexhaustible nature. The power generation by electric wind turbines depends on the speed of wind, flow direction, fluctuations, density of air, generator hours, seasons of an area, and wind turbine position. During a particular season, wind power generation access can be increased. In such a case, wind energy generation prediction is crucial for transmission of generated wind energy to a power grid system. It is advisable for the wind power generation industry to predict wind power capacity to diagnose it.

The present paper proposes an effort to apply artificial neural network technique for measurement of the wind energy generation capacity by wind farms in Harshnath, Sikar, Rajasthan, India.
\end{abstract}

\section{Keywords—wind; neural network; wind power forecasting}

\section{INTRODUCTION}

Wind is a pollution-free renewable energy source. It is the only natural source of energy available everywhere. The consumption of electricity is rapidly increasing in the world with growing economies. India is a developing country and its economy is growing in all areas [1]. The limited power generation capacity of hydro and coal prompts us to find other energy sources. Wind energy is an alternative source but its potential regions have not been identified completely in detail [2]. The wind energy generation capacity depends on variability of its speed. It is necessary to investigate and collect data regarding availability of wind energy in all regions of the country for preparation of an inventory. We can predict the wind energy generation power by using soft computing techniques. Due to the variable nature of wind speed, wind energy forecasting is a crucially important factor. The forecasting of wind energy generation capacity involves several modeling techniques that use weather and past wind energy generation data [3, 4]. In order to achieve the highest forecasting accuracy, the energy forecasting techniques should take appropriate data to show future trends. Researchers and scientists have developed a number of energy estimation and prediction techniques for wind energy produced by wind farms $[5,6,12]$. In their works, artificial intelligence methods such as neural networks [5] and fuzzy logic are found efficient and accurate in comparison to traditional statistical methods [3, 4, 10-17].

In this paper, a wind power forecasting method is presented based on the neural network methodology. The input parameters to this proposed model are wind speed, relative humidity, and generation hours. The output parameter is the generated wind energy by wind turbine. The wind energy relative accuracy is measured in terms of Mean Squared Error (MSE) and the Mean Absolute Error (MAE).

\section{WIND ENERGY STATUS IN RAJASTHAN}

USA ranks first amongst the wind energy generation countries in the world. The wind energy production capacity of India is $102,788 \mathrm{MW}$ at 50 meters above the ground level $[1,7]$. India holds the fifth position in the generation of wind energy after USA, China, Germany, and Spain. The state of Rajas than is in the northwestern part of India. It is located between $23^{\circ}$ and $30^{\prime}$ and $30^{\circ}$ and $11^{\prime}$ on the northern latitude and $69^{\circ}$ and $29^{\prime}$ and $78^{\circ}$ and $17^{\prime}$ on the east longitude. It covers 132,140 square miles of total geographical area and the largest state of India. The transmission power grids of Rajasthan connect to five neighbor states through $400-\mathrm{KV}$ lines. It has a capacity of $3593.745 \mathrm{MW}$ power generations by nuclear, hydropower, and thermal [8]. The location of the Aravali mountain range in Rajasthan along the north east to south west is favorable for wind energy generation. A total wind power generation capacity of $1639 \mathrm{MW}$ is achieved by India including, Tamil Nadu- 895MW, Maharashtra- 399MW, Gujarat- 166 MW, Andhra Pradesh 92.6 MW, Karnataka93.00 MW, and Rajasthan - 60 MW. The state of Rajasthan has a gross potential of $5400 \mathrm{MW}$ and technical potential of $845 \mathrm{MW}$ of wind energy [7, 9]. Rajasthan has experienced less attraction for private sector compared to other states in India to generate wind power. The Harshnath mountain region in the Sikar district of Rajasthan is a unique location for positioning all wind turbines on a single place with installed capacity of $12 \mathrm{MW}$. The wind turbines are scattered along the Harshnath from Goreia village to the Jeenmata temple. The winds of south west monsoon blow at an average speed of 11.5-12.5 $\mathrm{m} / \mathrm{s}$ from June to August. The wind blows at an average speed of $5.5-6.5 \mathrm{~m} / \mathrm{s}$ yearly in this area.

\section{ANALYSIS OF AVAILABLE WIND POWER}

The wind turbine generates wind power as kinetic energy. The density of air and speed directly influence the generation 
power of wind capacity [1]. The power generation is calculated as

$$
\mathrm{P}_{\text {wind }}=\frac{1}{2} \sigma \mathrm{A} \mathrm{V}^{3}
$$

The wind power $\mathrm{P}_{\text {wind }}$ is proportional to $\sigma$ air density in $\mathrm{kg} / \mathrm{m}^{3}$, A denotes the swept area of wind turbine in $\mathrm{m}^{3}$, and $V$ is up stream wind speed in meter per second, The turbine power output influences on the wind capacity because power is cubic proportional to wind speed in watts. The air density variation can be measured diversely during entire year on various locations. It has lesser diversity in comparison to wind variation. The wind turbine power production capacity is proportional to wind speed during all the seasons of a year [10]. The design specification of the wind turbine controls the power generation capacity such as length of blade and cut in speed, the lowest wind speed to start the turbine for generating useful power, rated wind speed on which the machine generates the rated wind generation, and cut-out speed that allows production of maximum power [11]. In general, the cut-in speed of air is accepted by the wind turbine between 2.5 $\mathrm{m} / \mathrm{s}$ to $3.5 \mathrm{~m} / \mathrm{s}$ and the cut-out speed is in the range of 20 to 25 $\mathrm{m} / \mathrm{s}$. The wind farm generates rated power when wind speed received by the machine is higher than rated wind speed (approximately $14 \mathrm{~m} / \mathrm{s}$ ). The average power generation capacity of wind farms fluctuated between 0.25 at $7.60 \mathrm{~m} / \mathrm{s}$ to 0.044 at $2.85 \mathrm{~m} / \mathrm{s}$ in monthly basis. It clearly shows the variation in wind energy and an area of research for prediction of wind energy.

\section{INPUT PARAMETERS FOR WIND POWER GENERATION}

The setting of input parameters in neural network system is a crucial task for prediction of wind energy. Different parameter values might yield very different power generation results. A good setting of parameters for a neural network system may give best solution within a reasonable time period.

The input parameters of wind energy prediction system are wind energy generated, generation hours, temperature, average pressure, and relative humidity. The average-monthly input parameters of neural network based forecasting system are relative humidity, wind speed, and generation hours. All the input parameters are collected for wind power calculation and analysed to define relationship between the input and output by using correlation method. The output parameter of forecasting is highly dependent on two input parameters, average wind speed and the generator hours with a high correlation values. The relative humidity has a weak affect on the output parameter with a moderate correlation. The two input parameters called average temperature and average pressure have not been examined during modeling neural networks because both parameters have low variations. The input parameter relative humidity of wind depends on the amount of water vapor in the air and it has an effect on the air density [1]. The air density is inversely proportional to relative humidity. The air density is calculated as

$$
\mathrm{D}_{\text {Air density }}=d\left(\frac{273.15}{T}\right) \times\left[\frac{B-0.3783 e}{760}\right] \text {. }
$$

Here $d$ represents the density of the dry air at atmospheric temperature $\left(25^{\circ} \mathrm{C}\right)$ and standard pressure $(100 \mathrm{kPa})(\mathrm{d}=$ $1.168 \mathrm{~kg} / \mathrm{m}^{3}$.

The air density is inversely proportional to $T$ absolute temperature (Kelvin) and directly proportional to the barometric pressure $\mathrm{B}$ (torr). The symbol $e$ is vapor pressure of moist air in torr. The proposed neural network wind power forecasting system takes three input parameters, wind speed, relative humidity and generation hours.

TABLE I. WIND GENERATORS CAPACITY

\begin{tabular}{|l|l|l|l|l|l|l|}
\hline $\begin{array}{l}\text { Wind } \\
\text { generator }\end{array}$ & WG1 & WG2 & WG3 & WG4 & WG5 & WG6 \\
\hline $\begin{array}{l}\text { Capacity } \\
\text { (MW) }\end{array}$ & 0.60 & 0.60 & 0.60 & 0.60 & 0.60 & 0.60 \\
\hline
\end{tabular}

\section{NEURAL NETWORK FORECASTING SYSTEM FOR WIND ENERGY}

\section{A. Biological Neuron}

Human neuron system, a biological neuron receives inputs from all parts of body, combines the inputs, performs a nonlinear operation and gives the final output result. Figure 1 depicts the correlation of these parts.

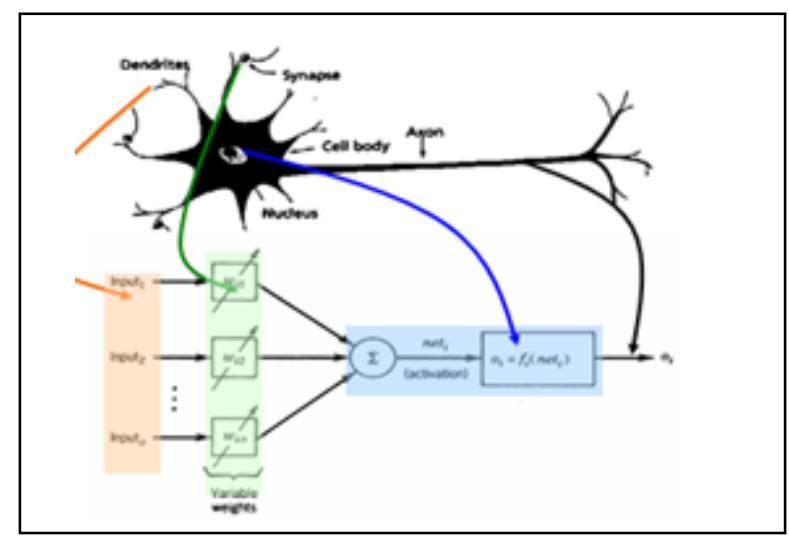

Fig. 1. A correlation between biological neuron and ANN

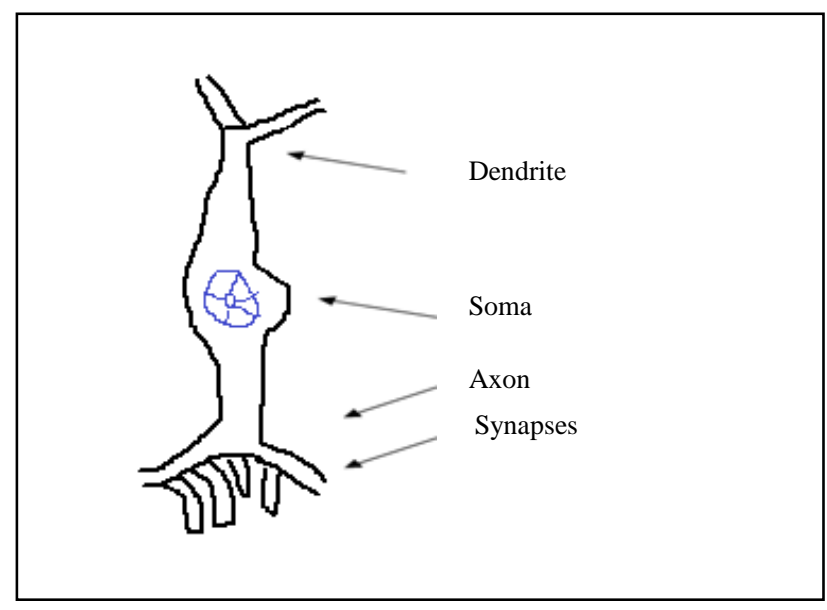

Fig. 2. A Neuron Components 
In our body system, there are many variations of different neurons. A neuron consists of four components known as soma, dendrites, axon, and synapses as shown in Figure 2. The dendrite is very thin like hair and is an extension of the soma and works as input channels [5]. It receives its input signals through the synapses of other neurons of our human body. The soma processes these incoming signals and sends to other neurons through the axon and the synapses.

\section{B. Artifical Neural Network}

An Artificial Neural Network (ANN) is a type of model that was first abstracted by McCulloch and Pitts [5]. ANNs were designed on biological neurons system, and how neurons interact with each other in the brain. Kilogram stated that during the past years, there has been a substantial increase in the interest on the ANNs. The scientists and researchers have designed and developed ANN systems for application in various areas of social sciences, physical science, and engineering, medicine and many other areas [5]. The neural network based system needs to train on an input data set known as training data set. Thereafter, the system is tested by using test data set and this process is known as testing. Its results are validated before prediction of data sets [12]. The ANN can be used to solve complex applications that are not possible by the traditional approaches and difficult to model analytically $[14,15]$. The basic processing unit of an artificial neural network is a neuron. It takes input, processes on input and gives output. The ANN can be designed using either feed forward or feedback approach. There are three types of layers, input layer, hidden layer, and output layer in an ANN $[13,16]$. The ANN neuron model is depicted in Figure 3. Each input $i$ to neuron has an associated weight $w_{i}$. A neuron $j$ can be mathematically represented by the following expressions [5].

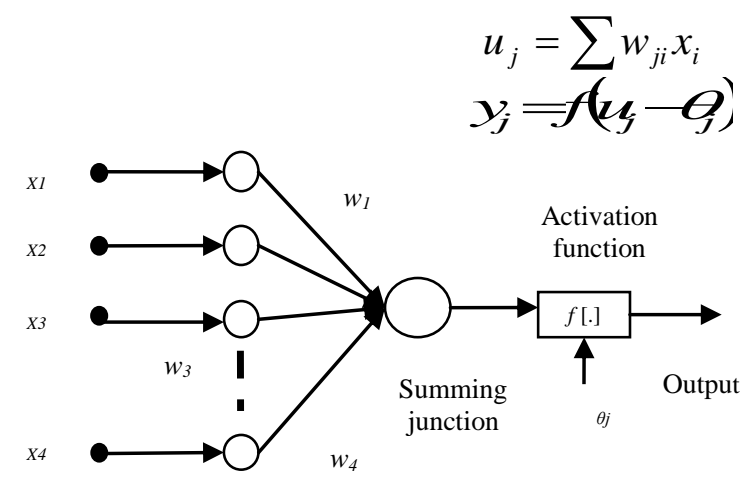

Fig. 3. Neuron model

\section{ANN Architecture for Wind Energy}

The proposed neural network for wind power forecasting model is a feed forward network model with supervised learning using back propagation algorithm [5]. The overall structure of wind power forecasting model is 3-4-1 as shown in Figure 4. The input layer receives three inputs, average wind speed, average relative humidity, and average generation hours per month, processed by three processing units. We set bias value equal to zero during calculation in activation functions. We have adopted the logarithmic sigmoid function as activation function at the second layer and linear activation function at the output layer. The weights at each of intermediate and output layer are adjusted in the training mode until the errors are detected within the pre specified range. The output parameter is the wind energy generation by the wind farms. The proposed model is implemented using MATLAB to forecast wind energy by wind generators as shown in Figure 4. The wind power forecasting model has trained in batch mode [19]. The batch training is typically done in train mode and inputs are dynamically converted into concurrent vectors. A new vector generates to show how close the input is to the target vector. The input parameters values are scaled within the range of $0-1$ during normalization.

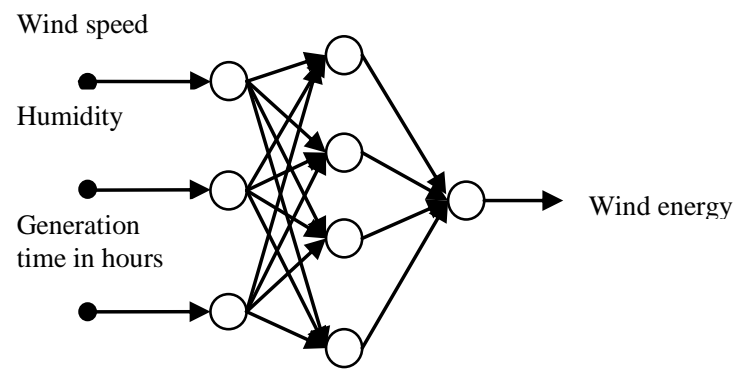

Fig. 4. ANN Architecture for wind energy forecasting

\section{Training performance and accuracy of the Prediction}

In the proposed wind power forecasting system to determine quantitatively evaluation of the model, two error detection methods are used. The accuracy of model can be determined by mean squared error (MSE) as shown in (6) and mean absolute error (MAE) as shown in (7) $[1,5]$. The MAE is a quantity method used to measure how forecasts are close to each other. In this model, we trained the neural network in range from 10 - min, to 60 -min time delay modes. $y_{t}$ is the $t_{\text {th }}$ observation of the actual wind power measurement and $F_{\mathrm{t}}$ is predicted wind power for same period of time $t$. The actual wind power production by turbine is presented in Table 2. The error $e_{t}$ can be calculated as in (5).

$$
\begin{gathered}
\varepsilon_{\tau}=\psi_{\tau}-\Phi_{\tau} . \\
\mathrm{MSE}=\frac{1}{n} \sum_{i=1}^{n} \boldsymbol{e}_{t}^{2}, \\
\mathrm{MAE}=\frac{1}{n} \sum_{i=1}^{n}\left|\boldsymbol{e}_{t}\right|,
\end{gathered}
$$

where $n$ is length of vector for wind power forecast data. When the MSE is reduced in a gradual way and its became stable, than wind power forecast model gives satisfactory results on training and testing data sets. Figure 5 shows the training accuracy of wind power forecast model. The performance of the forecasting network is tested by using actual wind energy output. The accuracy is assessed using two methods. In the first method, the forecasted wind power output is compared with the actual wind power production. Figure 6 shows accuracy of the forecasted wind power generation per hour. The average percentage error analysis is 7. In the second method, RMSE MAE are measured and analysed. The error estimation using MAE and MSE statistics of the forecasting results are shown in Table 2. The goal set of MSE is 0.0001 . The proposed model has been run for 1200 iterations but MSE of training data set become static at 0.0070 
after 300 iterations. Figure 6 shows predicted and actual wind power representation. The predicted and actual wind power results closeness shows the accuracy of forecasting model.

TABLE II. ERROR ANALYSIS

\begin{tabular}{|c|c|c|}
\hline Input (MW) & MAE & MSE \\
\hline $10 \mathrm{~min}$ & 4.82 & 8.20 \\
\hline $20 \mathrm{~min}$ & 5.45 & 9.15 \\
\hline $30 \mathrm{~min}$ & 6.55 & 10.30 \\
\hline $40 \mathrm{~min}$ & 7.15 & 11.25 \\
\hline $50 \mathrm{~min}$ & 8.25 & 12.00 \\
\hline $60 \mathrm{~min}$ & 9.35 & 13.50 \\
\hline
\end{tabular}

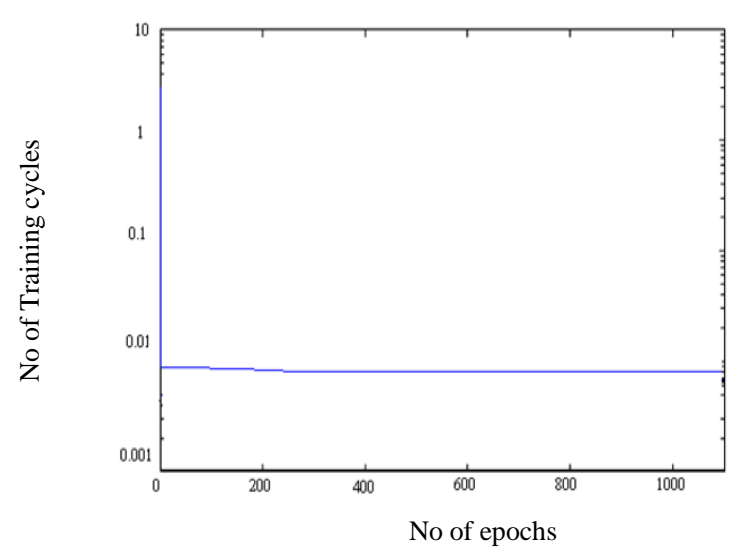

Fig. 5. Training performance of the neural network

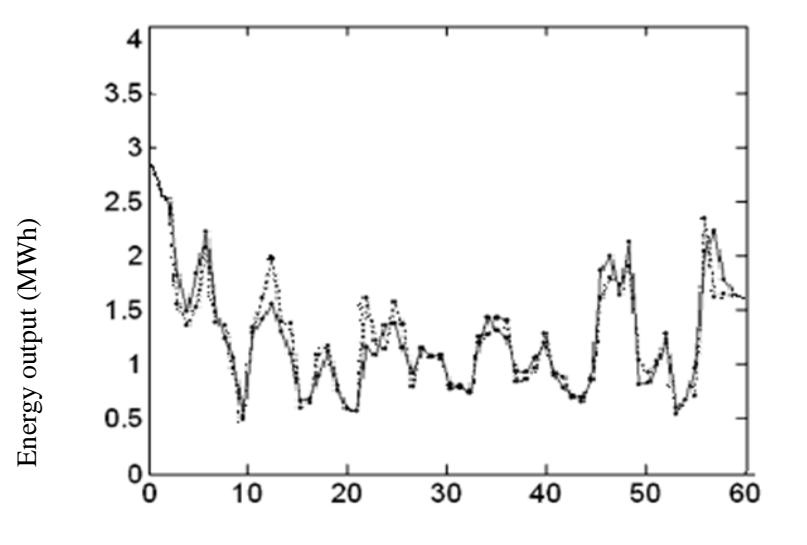

Time points of 10 minutes

Fig. 6. Measured and predicted wind power

\section{CONCLUSION}

This paper presents a wind power forecasting model based on feed forward neural network architecture. The back propagation algorithm was applied to trained proposed model using supervised learning technique. The data are divided in two sets, training data and test data for testing accuracy of proposed model. The input parameters, average wind speed, average relative humidity, and generation hours are collected from various sources.
The performance of model is measured by using two errordetection methods, MSE and MAE. The proposed model was run at different iteration both on training and testing data sets. The MSE becomes stable at 0.0070 at 300 iterations. The proposed model wind power prediction shown in Figure 6 indicates its capability of forecasting. It proves to be an efficient and valuable tool for the estimation of wind energy for wind generators.

\section{REFERENCES}

[1] Mabel MC, Fernandez E. Analysis of wind power generation and prediction using ANN: a case study. Renewable Energy, Vol. 33(5):98692, 2008.

[2] F. Manwell, J. G. McGowan, and A. L. Rogers, Wind energy explained: theory, design and application. New York: Wiley, 2002.

[3] Shuhui Li, Donald C. Wunsch, Edgar A. O'Hair and Michael G. Giesselmann, Using neural networks to estimate wind turbine power generation, IEEE Trans. on Energy Conversion, vol. 16, pp.267-282, 2001.

[4] Andrew Kusiak, Haiyang Zheng and Zhe Song, Short-term prediction of wind farm power: a data mining approach, IEEE Trans on Energy Conversion, vol.24, no.1, pp.125-135, 2009.

[5] S. Haykin, Neural networks, a comprehensive foundation, New Jersey, 2nd edition, 1999.

[6] D. A. Bechrakis and P. D. Sparis. Correlation of wind speed between neighboring measuring stations, IEEE Trans. Energy Convers., vol. 19(2), pp. 400-406, 2004.

[7] Wind power in India, http://www.windpowerindia.com/index.php [accessed on 01.02.16].

[8] Ministry of new and renewable energy, http://www.mnre.gov.in/ [accessed on 01.01.16]

[9] S. Mani, T. Dhingra. Policies to accelerate the growth of offshore wind energy sector in India. Renewable and Sustainable Energy Reviews, vol 24 (c), pp. 473-482, 2013.

[10] Lei, M., Shiyan, L., Chuanwen, J., Hongling, L., and Yan, Z. A review on the forecasting of wind speed and generated power. Renewable and Sustainable Energy Reviews, vol 13(4), 915-920, 2009.

[11] Kaldellis, John K., and D. Zafirakis. The wind energy (r) evolution: A short review of a long history. Renewable Energy, vol 36, no. 18871901, 2011.

[12] Indu R. Pillai, Rangan Banerjee, Renewable energy in India: Status and potential, Energy, vol 34(8), pp. 970-980, August 2009.

[13] T. G. Barbounis, J. B. Theocharis,M. C. Alexiadis, and P. S. Dokopoulos. Long-term wind speed and power forecasting using local recurrent neural network models, IEEE Trans. Energy Convers., vol. 21, no. 1, pp. 273-284, 2006.

[14] Bilgili, M., Sahin, B., \& Yasar, A. Application of artificial neural networks for the wind speed prediction of target station using reference stations data. Renewable Energy, vol 32(14), 2350-2360, 2007.

[15] P. Flores, A. Tapia, and G. Tapia. Application of a control algorithm for wind speed prediction and active power generation, Renewable Energy, vol. 30, pp. 523-536, 2005.

[16] Fadare, D. A. The application of artificial neural networks to mapping of wind speed profile for energy application in nigeria. Applied Energy, vol 87(3), 934-942, 2010.

[17] Pourmousavi Kani, S. A., and Ardehali, M. M. Very short-term wind speed prediction: a new artificial neural network-markov chain model. Energy Conversion and Management, vol 52(1), 738-745, 2011.

[18] Mahamad, Nurhashinmah, and Muhamad Kamal B. Mohammed Amin. Power prediction analysis using artificial neural network in $\mathrm{ms}$ excel. 7th International Conference on Latest Trends in Renewable Energy and Environmental Informatics, Malaysia, pp 54-58, 2013.

[19] Karabacak, K., and Cetin, N. Artificial neural networks for controlling wind-pv power systems: a review. Renewable and Sustainable Energy Reviews, vol 29, 804-827, 2014. 